Journal of Behavioral Decision Making

J. Behav. Dec. Making, 17: 281-295 (2004)

DOI: $10.1002 / \mathrm{bdm} .472$

\title{
The Affective Costs of Overconfidence
}

\author{
A. PETER McGRAW ${ }^{1} *$, BARBARA A. MELLERS ${ }^{2}$ and ILANA RITOV ${ }^{3}$ \\ ${ }^{1}$ University of Colorado, USA \\ ${ }^{2}$ University of California, Berkeley, USA \\ ${ }^{3}$ Hebrew University, Jerusalem, Israel
}

\begin{abstract}
Positive illusions, though often beneficial (Taylor \& Brown, 1988), can diminish the pleasure of outcomes. This prediction follows from decision affect theory. We investigated this prediction by measuring the confidence that recreational basketball players felt while making shots and the pleasure they felt with subsequent outcomes. Results showed that most players were overconfident. Those who were more overconfident tended to experience less enjoyment with their outcomes. Using individual parameter estimates from decision affect theory, we estimated how each player would have felt if their self assessments had been accurate. For the vast majority, better calibration would have led to greater pleasure. In a second study, we randomly assigned players to a debiasing treatment condition or a control condition. Relative to the control players, debiased players were better calibrated and derived greater average pleasure from the task. Copyright (C) 2004 John Wiley \& Sons, Ltd.
\end{abstract}

KEY WORDS overconfidence; optimism; positive illusions; affect; emotions; pleasure; debias

Most people view themselves through rose-colored glasses (Baumeister, Tice, \& Hutton, 1989; Greenwald, 1980). They believe their future holds more favorable outcomes and fewer unfavorable outcomes than those of their peers (Weinstein, 1980). They believe they are superior to others on most socially desirable dimensions (Alicke, 1985). They believe they can influence and even control situations governed largely by chance (Langer, 1975; Langer \& Roth, 1975), and they believe their successes and failures are due to skill and bad luck, respectively (Cohen, 1964; Weiner, 1985; Wortman, Costanza, \& Witt, 1973).

Positive illusions can have advantages, such as increasing motivation, raising aspiration levels, and strengthening coping mechanisms in the face of negative feedback (see Taylor \& Brown, 1988). However, a growing literature questions the generality of the beneficial association between positive illusions and mental health (e.g., Colvin, Block, \& Funder, 1995; Paulhus, 1998). Others claim that positive illusions are disadvantageous, and even harmful, when they lead to poor judgment, disengagement (Robins \& Beer,

\footnotetext{
* Correspondence to: Peter McGraw, Leeds School of Business, University of Colorado, 419 UCB, Boulder, CO 80309, USA.

E-mail: peter.mcgraw@colorado.edu

Contract/grant sponsor: NSF, USA; contract/grant number: SBR-96-15993.

Copyright (C) 2004 John Wiley \& Sons, Ltd.
} 
2001), the pursuit of unreasonable goals (Kahneman \& Lovallo, 1993), and suboptimal negotiations (Neale \& Bazerman, 1985). We add to this literature by demonstrating the emotional costs of positive illusions; overly optimistic beliefs can diminish the pleasure of outcomes.

\section{OVERCONFIDENCE}

Researchers in decision making have examined people's ability to match their probability judgments of the relative frequency of an event (e.g., ratings of confidence) to the actual likelihood of that event (e.g., accuracy). People are said to be 'well-calibrated' if their average confidence is approximately equal to the relative frequency of that event. Such studies have often used tests of general knowledge, and the results show that people are overconfident in their beliefs. Average confidence is typically higher than performance actually dictates (Baron, 1994; Hazard \& Peterson, 1973; Lichtenstein, Fischhoff, \& Phillips, 1982; Phillips \& Wright, 1977; Yates, 1990).

Another kind of calibration study examines people's assessments of their future ability to perform a task. We will focus on this type of calibration, which has its basis in positive illusions. Exaggerated perceptions of personal control and unrealistic optimism often give rise to inflated assessments of one's ability to perform a task (Bazerman, 2002; Kahneman \& Lovallo, 1993; Yates, 1990). For example, novice bridge players are overconfident when predicting their likelihood of success (Keren, 1987). Entrepreneurs also believe that their chances of building a successful business are higher than what would be expected given the statistical odds (Cooper, Woo, \& Dunkelberg, 1988). Such tendencies also extend to judged physical ability. A wellknown example of this is that automobile drivers believe they are safer and more skilled behind the wheel than their peers (Svenson, 1981). Even when individuals excel in a task, such as skilled basketball players, they are overly optimistic about their chances of future success (Jagacinski, Isaac, \& Burke, 1977).

\section{EXPECTATIONS AND PLEASURE}

Overconfidence reflects a systematic discrepancy between expectations and reality. Moreover, expectations, both accurate and inaccurate, influence our emotional experiences. Expectations serve as reference points that arise from personal goals or desires (Kunda, 1990), counterfactual possibilities (Kahneman \& Tversky, 1982; Roese \& Olson, 1995), or the outcomes of relevant peers (Tesser, 1988). Furthermore, the strength of one's beliefs (i.e., confidence) in an expected outcome influences one's emotional experiences. The connection between strength of belief and pleasure is formalized in an account called decision affect theory (Mellers, Schwartz, Ho, \& Ritov, 1997; Mellers, Schwartz, \& Ritov, 1999; Mellers, 2000). In this account, affective experiences depend on actual outcomes, expected outcomes, and confidence.

This paper explores the effects of exaggerated optimism on affective experience using a shooting drill with basketball players. This task has three desirable properties. First, most players tend to be overconfident in their ability (Jagacinski et al., 1977). Second, it is easy to apply decision affect theory to describe the emotional experiences of players. Third, with the help of debiasing procedures, players can reduce their overconfidence.

When a player attempts a shot, there are two possible outcomes - success or failure. Decision affect theory predicts their emotional reaction to either outcome. The theory can be expressed as

$$
\hat{R}_{O}=J\left[u_{O}+c_{O, E} *\left(1-s_{O}\right)\right],
$$

where, $\hat{R}_{O}$ is the judged pleasure of an obtained outcome, $J$ is a linear function relating a feeling of pleasure to a numerical response, $u_{O}$ is the utility of the obtained outcome, and $c_{O, E}$ is a function representing 
comparison effects between the obtained and the unobtained (often expected) outcomes. With only two outcomes, comparison effects can be represented as an asymmetric step function. ${ }^{1}$ Numerous studies show that negative comparisons have a greater impact on pleasure than positive comparisons (Mellers et al., 1997, 1999; Mellers \& McGraw, 2001). Finally, decision affect theory predicts that the comparison function is weighted, or strengthened, by one's lack of confidence in the obtained outcome, $\left(1-s_{O}\right)$. We refer to this feeling of unexpectedness as 'surprise.'

The predicted effect of confidence on pleasure is reminiscent of past literature on achievement motivation (Atkinson, 1957, 1983; McClelland, 1961). Achievement motivation theory asserts that the pleasure of a success is inversely related to the probability of that success. Very difficult tasks yield great pleasure, and very easy tasks provide virtually no pleasure. When people are focused on a future success, they tend to choose intermediate levels of task difficulty where the expected pleasure is greatest. When people are focused on failure, they choose either very easy tasks (with little chance of failure) or very difficult tasks (with little chance of success and no shame in failing). Though successful at predicting a selected level of difficulty, achievement motivation theory does not address the influence of mental comparisons on pleasure, nor does it permit asymmetries in positive and negative comparisons (McGraw, 2003).

Decision affect theory handles these concerns. The theory was initially tested as an account of the judged pleasure of monetary outcomes (Mellers et al., 1997, 1999). It described the anticipated and actual pleasure of wins and losses. Holding all else constant, larger wins produced greater pleasure, but when a win or a loss fell short of a reference point, pleasure decreased. Furthermore, smaller wins could evoke greater pleasure than larger wins, depending on the reference points both within and across gambles. Last but not least, the unexpectedness of an outcome amplified the mental comparisons with salient reference points. Surprising wins were more pleasurable than expected wins, and surprising losses were more painful than expected losses.

Mellers and McGraw (2001) extended decision affect theory in observational studies with non-monetary outcomes. Decision affect theory could describe the affective experiences of undergraduates upon receiving their final grades in a psychology class, clients in a commercial weight loss program after learning their weekly weight changes, and women learning the results of their pregnancy tests at Planned Parenthood. In each domain, pleasure was influenced by actual outcomes, expected outcomes, and confidence (or the strength of one's belief in an outcome). Shepperd and McNulty (2002) found similar effects in studies of grades, medical test results, and salary raises.

\section{OVERVIEW}

Decision affect theory makes no predictions about the degree to which people are calibrated. Instead, it explains how discrepancies between expectations and actual outcomes will influence affect. As the gap increases between what one believes will occur and what actually occurs, emotional reactions are amplified. Overconfident people expect successes, and expected successes are less pleasurable than surprising successes. Furthermore, overconfident people are surprised by failure, and surprising failures are more painful than expected failures. In the studies that follow, we examine these implications of decision affect theory.

In Study 1, we measured players' confidence of success before each shot and affective reaction after each shot. Using decision affect theory, we predicted how mисh better players would have felt about their performance if they had been accurately calibrated. In Study 2, we used a debiasing procedure to manipulate confidence and investigated the effects of better calibration on pleasure.

\footnotetext{
${ }^{1}$ In past research, we have also represented the comparison function as power function of the difference between utilities of actual outcomes and expected outcomes (e.g., Mellers et al., 1997, 1999).
} 


\section{STUDY 1: BASKETBALL SHOOTING DRILL}

Participants were recreational basketball players who agreed to take part in a shooting drill. Forty-five undergraduates at Ohio State University received partial course credit for their participation. The experiment took place at the campus gymnasium, and each drill was performed individually. After a warm-up period during which participants took several practice shots, they attempted 36 shots in a random order. Three shots were taken from each of the twelve marked distances shown in Figure 1. They rated their confidence of success before each shot and judged their pleasure with the outcomes after each shot.

Before each shot, participants rated their confidence of success on a scale from 0\%, 'Absolutely Certain I Will Not Make the Shot,' to 100\%, 'Absolutely Certain I Will Make the Shot.' Participants were instructed to think about the percentage of shots they would make from each spot when making their confidence judgments. After each shot, participants rated their feelings about the outcome using a scale from 9, labeled 'Very Good,' to -9 , labeled 'Very Bad.'

\section{Results and discussion}

Figure 2 shows average pleasure ratings for basketball players plotted against confidence of success. Confidence judgments were converted into eleven categories from 0 (no confidence) to 1.0 (certain confidence). The average emotional reactions associated with each confidence category are shown separately for successes and failures. Solid points with solid lines are data, and open points with dashed lines are predictions of decision affect theory. Error bars represent one standard error above and below each point. As shown in Figure 2, successes were more pleasurable than failures. Moreover, confidence influenced pleasure; when outcomes were expected, successes were less pleasurable and failures were less painful.

The slopes of the lines in Figure 2 represent comparison effects. Players derived pleasure from their successes by comparing them to failures, and they experienced displeasure from their failures by comparing them to successes. The slope for missed shots or failures (reflecting negative comparisons) is steeper than the slope for made shots or successes (reflecting positive comparisons). Negative comparisons had a greater influence than positive comparisons (see Baumeister, Bratslavsky, Finkenauer, \& Vohs, 2001; Rozin \& Royzman, 2001).

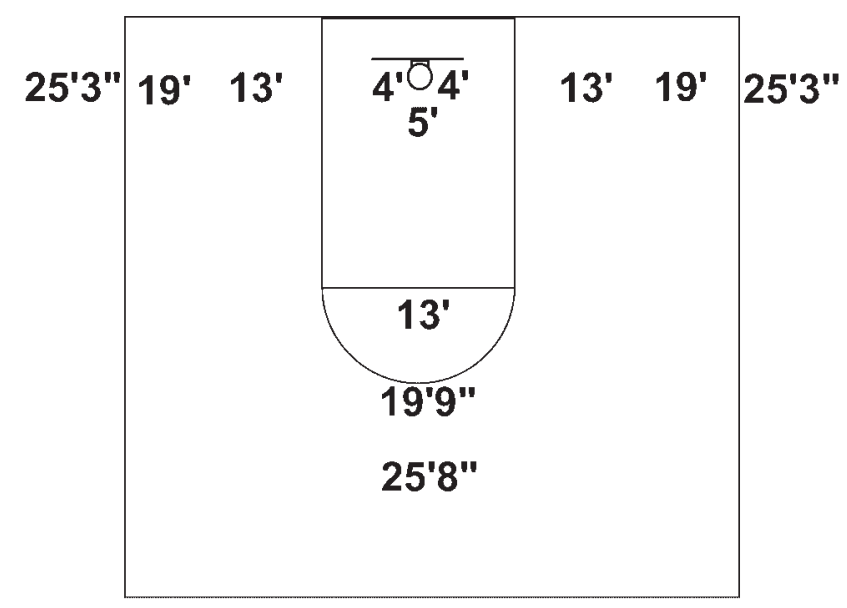

Figure 1. Distances and positions of shots attempted by recreational basketball players on the basketball court. Distances were measured from the marked spot to a point directly beneath the center of the basket 


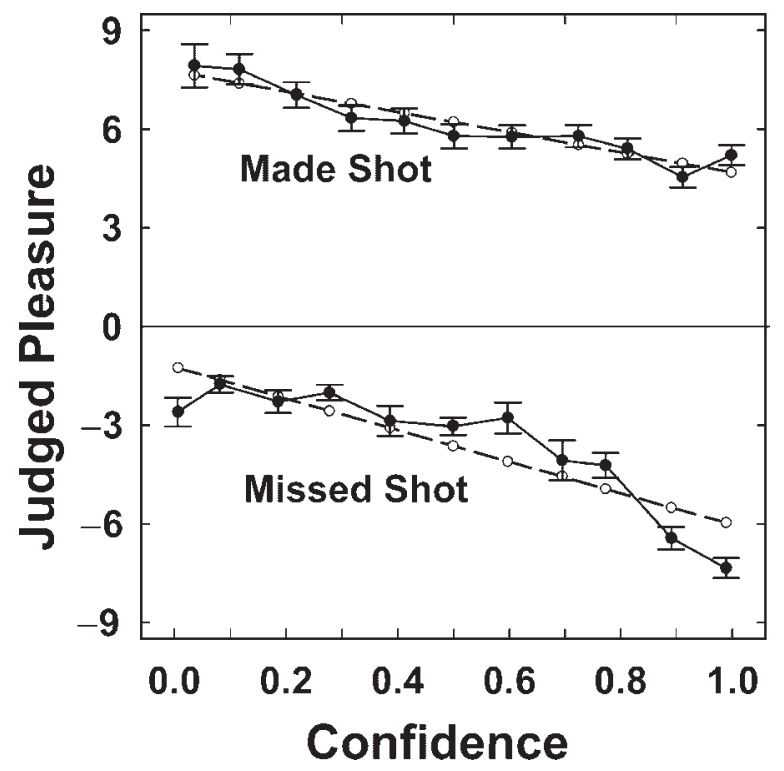

Figure 2. Recreational basketball players' judged pleasure and displeasure are displayed for successes and failures, respectively. Affective responses are plotted against confidence of success. Solid points with solid lines are data, and open points with dashed lines are predictions of decision affect theory. Slopes reflect comparison effects between obtained and unobtained outcomes. Error bars show one standard error above and below each point

To test decision affect theory, we fit Equation 1 to average ratings of pleasure. Using Microsoft Excel's Solver, we estimated least squares parameters of the theory by minimizing the sum of the squared errors between data and predictions. Although levels of confidence, $s_{O}$, are shown as parameters in Equation 1, we did not estimate these parameters. Instead, we used observed confidence ratings to reduce the number of estimated parameters. In this form, the theory required four parameters, including two values of $u_{O}$ (utilities of success and failure) and two values of the comparison function, $c_{O, E}$, one for negative comparisons and the other for positive comparisons.

Decision affect theory accounted for all but $2 \%$ of the variance in the mean judgments. Predictions, shown as dashed lines, fell close to the data. Estimated values of the comparison function were asymmetric; positive and negative comparisons were 3.4 and -4.8 , respectively, on a -9 to +9 response scale. We also fit decision affect theory to individual subject data. The proportion of residual variance ranged from $1 \%$ to $23 \%$ across the 45 participants, with a median residual variance of $11 \%$. Individual data revealed patterns that were similar to those found in the means. For the majority of players (67\%), negative comparisons had a greater effect than positive comparisons.

Standard statistical tests supported the predictions of the model. Individual judgments of pleasure were regressed on outcome, confidence of success, and the interaction of outcome and confidence. Subject was included as a covariate to account for individual differences in responses. All beta weights in the regression differed significantly from zero. Judged pleasure increased with made shots $(t=21.4)$ and with lower confidence $(t=12.7)$. Lastly, higher confidence had a bigger effect on failures than successes, due to the greater effect of negative comparisons $(t=3.2){ }^{2}$

\footnotetext{
${ }^{2}$ All statistical tests are significant at the 0.05 level unless otherwise noted.
} 


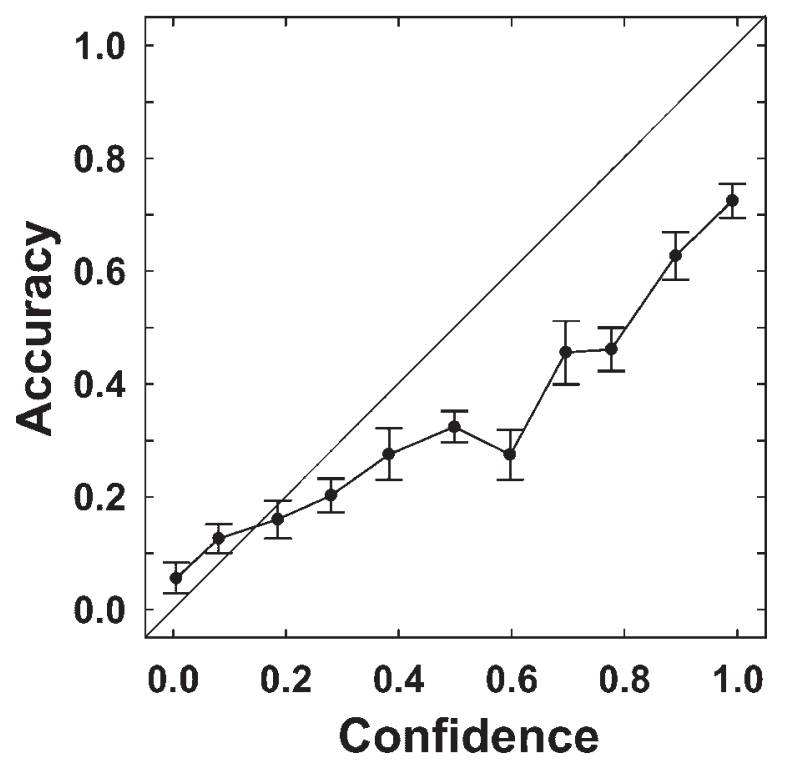

Figure 3. Accuracy of participants plotted against judged confidence for recreational basketball players. Individuals are, on average, overconfident. Error bars show one standard error above and below each point

How well did players predict their shooting performance? The majority was overconfident, with an average confidence of $52 \%$, and a success rate of only $36 \%$. Figure 3 shows the calibration plot that is typically used in tests of overconfidence. Shooting accuracy was presented as a function of average confidence for each of the 11 confidence categories. Error bars represent one standard error above and below the mean. If participants had been perfectly calibrated, points would have fallen along the identity line. All but two of the points fell below the line, revealing a general tendency toward overconfidence that increases with confidence. In fact, when shooters were $100 \%$ confident of their success, their accuracy rate was only $74 \%$.

Do overconfident players experience less pleasure? Figure 4 shows each player's average judged pleasure (over all shots) plotted against his calibration (i.e., average confidence minus accuracy rate). Positive numbers on the abscissa represent overconfidence, and negative numbers represent underconfidence. The figure shows that the majority of players were overconfident. Furthermore, overconfident shooters rated their pleasure lower than either calibrated or underconfident shooters $(r=-0.54)$.

How much better would players have felt if their beliefs had been accurate? To answer this question, we compared the average judged (actual) pleasure of each player with the average predicted pleasure that each player would have experienced with perfect calibration. The average predicted pleasure, $\hat{\bar{P}}$, is the proportion of actual successes times the predicted pleasure of the average success plus the proportion of actual failures times the predicted pleasure of the average failure:

$$
\hat{\bar{P}}=p_{S} * \hat{\bar{R}}_{S}+\left(1-p_{S}\right) * \hat{\bar{R}}_{F}
$$

where $\hat{\bar{R}}_{S}$ and $\hat{\bar{R}}_{F}$ are measures of the predicted pleasure of the average success and failure, respectively. Perfect calibration implies that, in $\hat{\bar{R}}_{S_{S}}$, the average lack of confidence in a success is equal to the proportion of missed shots (or $\left(1-p_{S}\right)$ ), and, in $\hat{\bar{R}}_{F}$, the average lack of confidence in a failure is equal to the proportion of made shots (or $\left(1-p_{F}\right)$ ). The predicted pleasure of the average success becomes the following:

$$
\hat{\bar{R}}_{S}=J\left[u_{S}+c_{S, F} *\left(1-p_{S}\right)\right]
$$




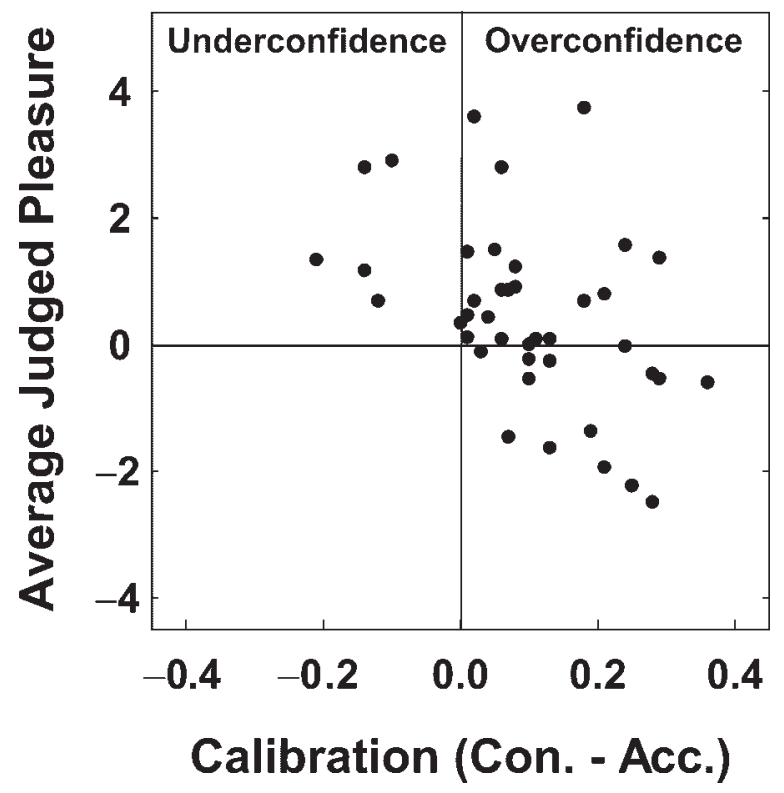

Figure 4. Average judged pleasure of each participant for the task plotted against calibration. Calibration is calculated by subtracting the participant's accuracy for the shooting task from average confidence. Data for underconfident and overconfident shooters are shown on the left and right side of the figure, respectively

and the predicted pleasure of the average failure follows suit:

$$
\hat{\bar{R}}_{F}=J\left[u_{F}+c_{F, S} *\left(1-p_{F}\right)\right] .
$$

Using individual proportions of successes and individual parameter estimates for $u_{S}$ and $c_{S, F}$ (for Equation 3) and $u_{F}$ and $c_{F, S}$ (for Equation 4), we estimated the predicted pleasure of the average success and average failure to get the average predicted pleasure that each player would have experienced with perfect calibration.

Figure 5 shows the average judgments of actual pleasure of a player plotted against average predicted pleasure of that player with perfect calibration. Although some points were quite close to the identity line, $80 \%$ of the points that deviated from the line were above it. Points above the line implied that players would have experienced greater overall pleasure with the task if they had accurately assessed their performance. ${ }^{3}$ The difference between the average judged actual pleasure and predicted pleasure across players was statistically significant. The actual mean was -0.12 over all players and the predicted mean was $0.70(t=4.8$; Cohen's $d=0.5){ }^{4}$

In summary, the results were consistent with decision affect theory and with our predictions. Judgments of pleasure in a shooting drill depended on outcomes, comparison effects, and confidence. Judged pleasure was linked to what actually occurred, what could have occurred, and one's confidence in what could have

\footnotetext{
${ }^{3}$ The analysis of changes due to calibration could also be conducted on decision affect theory predictions of average pleasure before calibration instead of average actual pleasure. The results would be nearly identical because average predicted pleasure before calibration was highly correlated ( $r=0.98$ in both tasks) with average actual pleasure.

${ }^{4}$ Cohen's $d$ is the mean of the difference scores divided by the standard deviation of the difference scores. Cohen's $d$ values of $0.2,0.5$, and 0.8 are interpreted as small, medium, and large effects (Cohen, 1977).
} 


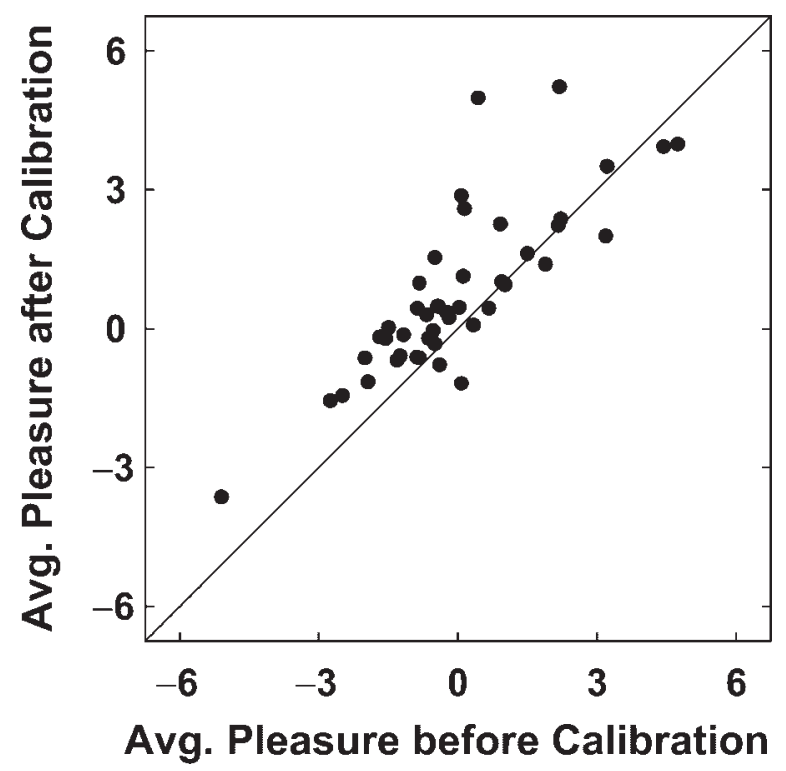

Figure 5. Average actual pleasure ratings (before calibration) plotted against average pleasure after calibration predicted by decision affect theory. The majority of points are above the identity line. This result implies that average affective experiences would increase if participants were better calibrated

occurred. The data were also consistent with previous research showing similar results with anticipated and actual emotions of bowlers (Coughlan \& Connolly, 2001).

In our basketball task, the overwhelming majority of players were overly optimistic as demonstrated by their overconfident predictions of performance. Decision affect theory predicts that overconfidence will have detrimental effects on pleasure; successes that are less surprising will be less pleasurable, and failures that are more surprising will be more painful. We demonstrated a negative correlation between overconfidence and average pleasure with the drill. The more overconfident the player, the lower he rated his pleasure. Finally, using decision affect theory, we estimated the change in overall pleasure that a player would have experienced if he had accurately assessed his ability. The data showed that, for most players, accurate selfassessments would have made the task more enjoyable. In Study 2, we investigated the causal link between overconfidence and pleasure by manipulating players' confidence.

\section{STUDY 2: DEBIASING BASKETBALL PLAYERS}

In this study, we randomly assigned players to one of two groups, a control group or a treatment group that was provided with additional information to make more accurate assessments of their own performance. Such debiasing attempts to reduce overconfidence in beliefs have not always been successful (Arkes, 1991). Yet some procedures have been effective, such as training and feedback (Lichtenstein \& Fischhoff, 1980), asking respondents to discuss their responses with peers (Arkes, Christensen, Lai, \& Blumer, 1987), and asking respondents to consider contrary evidence (Koriat, Lichtenstein, \& Fischhoff, 1980).

To debias our players of their overconfidence in their shooting ability, we told them about the general tendency toward overconfidence. We also told them the average accuracy rate at each location on the court for other recreational players like themselves. Then we examined whether the debiased group was better calibrated than the control group and explored the differences in pleasure. 


\section{Method}

Forty-two recreational basketball players from Ohio State University received partial course credit for their participation. Players were randomly assigned to either the debiased group $(n=22)$ or the control group $(n=20)$. There were a few changes in the drill from Study 1; spots on the court extended from the front of the basket toward the center of the court to save participants' time spent moving between locations. Distances were $1^{\prime}, 5^{\prime}, 9^{\prime}, 13^{\prime}, 17^{\prime}, 21^{\prime}$, and $25^{\prime}$. A practice drill was also included. Each participant attempted five shots from each spot in a predetermined random order.

After the practice drill, participants were given a five-minute break. At that time, the debiased group read about players' tendency to be overconfident in the shooting drill. Participants were informed that most players think they will be successful more often than they actually are and this overconfidence is greatest for shots that are close to the basket. They were asked to lower their confidence accordingly. In addition, accuracy rates from a previous pilot study were marked next to each spot on the floor. ${ }^{5}$ These accuracy rates were presented to give players guidelines to assess their own beliefs. The control players received no information about overconfidence or accuracy rates. After the break, all the players attempted five shots from each spot in a predetermined random order. They judged their confidence before each attempt and their feelings about the outcome after each attempt, using the same scales described in Study 1.

\section{Results and discussion}

Debiased players were significantly less confident than control players. On average, debiased players and control players were $48 \%$ and $57 \%$ confident, respectively $(t=2.8 ; d=0.9)$. Despite the possibility that lower expectations could lead to worse performance (e.g., Sherman, Skov, Hervitz, \& Stock, 1981), accuracy rates were similar across groups ( $44 \%$ and $41 \%$ for debiased and control groups, respectively). This difference was not statistically significant. Although both groups were overconfident, debiased players were less overconfident than control players (4\% and 16\%, respectively). Figure 6 presents calibration curves for the debiased and control groups, as shown in Figure 3. Error bars represent one standard error above and below each point. Debiased players fell closer to the identity line relative to controls and only deviate substantially when their confidence exceeded $75 \%$.

Did overconfident players experience less average pleasure with the task? Figure 7 shows each participant's calibration (average confidence minus accuracy rate) plotted against their average rating of pleasure, as in Figure 4. There was a negative correlation between overconfidence and average judged pleasure across the two groups $(r=-0.47)$. The most overconfident shooters had the lowest ratings of pleasure. Moreover, debiased players (open circles) reported feeling significantly more pleasure than control players (closed circles). The overall mean of the individual means for debiased players was 0.88 , whereas the overall mean for control players was only $0.04(t=2.0 ; d=0.6)$. The higher average judgment of pleasure for debiased players was due, in part, to the slightly better performance of the debiased players ( $44 \%$ vs. $41 \%$ ). We circumvented this difference by examining the average judged pleasure of a success and the average judged pleasure of a failure separately for each group. Debiased players and control players showed no differences in their feelings about successes $(M=5.0$ vs. $M=5.2$, respectively); however, they differed significantly in their feelings about failures. Debiased players were less displeased with failures than control players $(M=-2.7$ and -3.6 , respectively; $t=2.1 ; d=0.7)$. Better calibration led them to expect a lower likelihood of success and to derive more enjoyment from the task.

By teaching some players to be less overconfident, we were able to increase their pleasure in the basketball task relative to control players. Greater enjoyment did not come from better performance since the groups performed similarly. Instead, it came from less displeasure with failures. Why were there beneficial effects of

\footnotetext{
${ }^{5}$ The shooting percentage was $73 \%$ from $1^{\prime}, 65 \%$ from $5^{\prime}, 47 \%$ from $9^{\prime}, 40 \%$ from $13^{\prime}, 30 \%$ from $17^{\prime}, 20 \%$ from $21^{\prime}$, and $11 \%$ from $25^{\prime}$.
} 


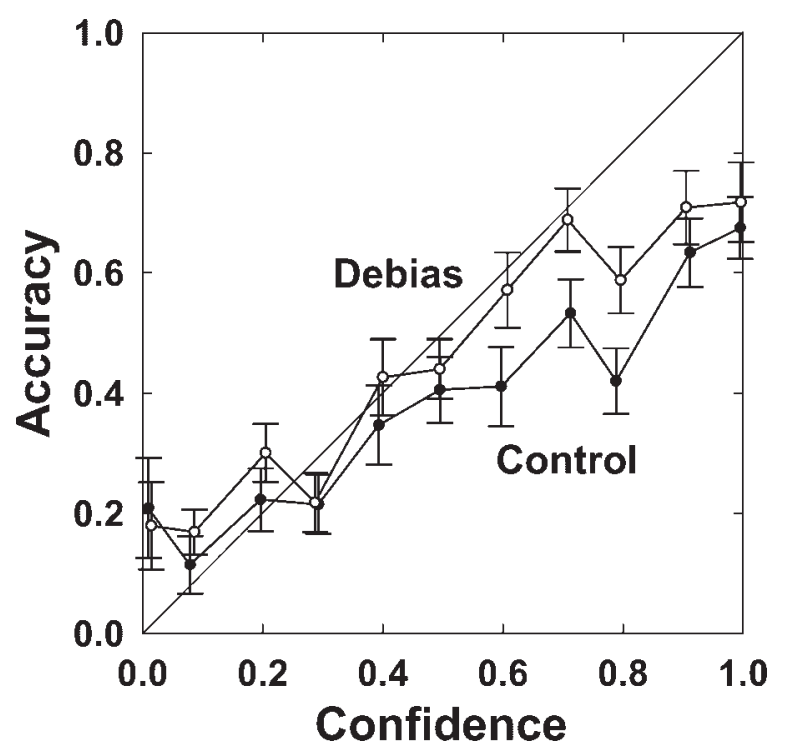

Figure 6. Accuracy of participants plotted against judged confidence. Separate curves show marked overconfidence for the control group and better calibration for the debiased group. Error bars show one standard error above and below each point

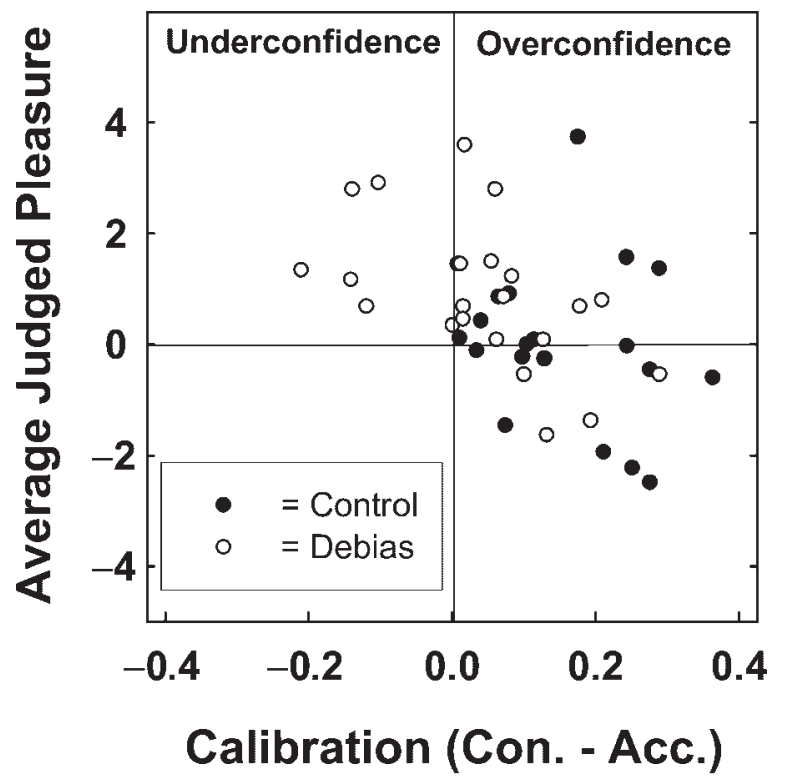

Figure 7. Average judged pleasure of each participant for the task plotted against calibration. Calibration is calculated by subtracting the participant's accuracy for the shooting task from average confidence. Darkened circles show the results for the control condition and open circles show results from the debias condition. Data for underconfident and overconfident shooters are shown on the left and right side of the figure, respectively 
calibration for failures but not for successes? Effects of confidence were greater for failures than successes, as seen by the steeper slope for missed shots relative to made shots in Figure 2. This pattern would be expected if surprise amplified comparison effects and if comparison effects were asymmetric. Indeed, negative comparisons had a greater influence than positive comparisons.

\section{GENERAL DISCUSSION}

The results of the present study show that overly optimistic beliefs can have detrimental effects on the pleasure of outcomes in a task of physical skill. Furthermore, debiased players who were told about overconfidence effects and were given base-rate information to guide their judgments enjoyed the task significantly more than control players. The increase in pleasure experienced by the debiased players arose largely from their emotional reactions to failures. This is expected if one's lack of confidence serves as a weight associated with the comparison between obtained and unobtained outcomes (see Equation 1), and if negative comparisons have a greater effect than positive comparisons.

If overconfidence makes us feel worse than we 'should' have felt about the outcomes of events, then how serious is this problem? Gilbert, Pinel, Wilson, Blumberg, and Wheatley (1998) suggest that the psychological immune system is fairly robust and people can quickly cope with negative outcomes. Moreover, people sometimes put a positive spin on a negative event when they are expecting a positive outcome (Klaaren, Hodges, \& Wilson, 1994). In short, our effects could be limited to relatively brief periods of time. We leave this topic open to future research.

The general question of whether people are overconfident in their beliefs is controversial (Ayton \& McClelland, 1997; Dawes \& Mulford, 1996; Keren, 1997). Applying these concerns to optimistic overconfidence raises the question of whether the calibration curves in Figures 3 and 6, which show overconfidence in predicted performance, really indicate overconfidence. Some researchers argue that overconfidence is an artifact of regression (Erev, Wallsten, \& Budescu, 1994; Budescu, Erev, \& Wallsten, 1997). Examining if overconfidence is evident in mean confidence ratings and accuracy rates can test the regression explanation.

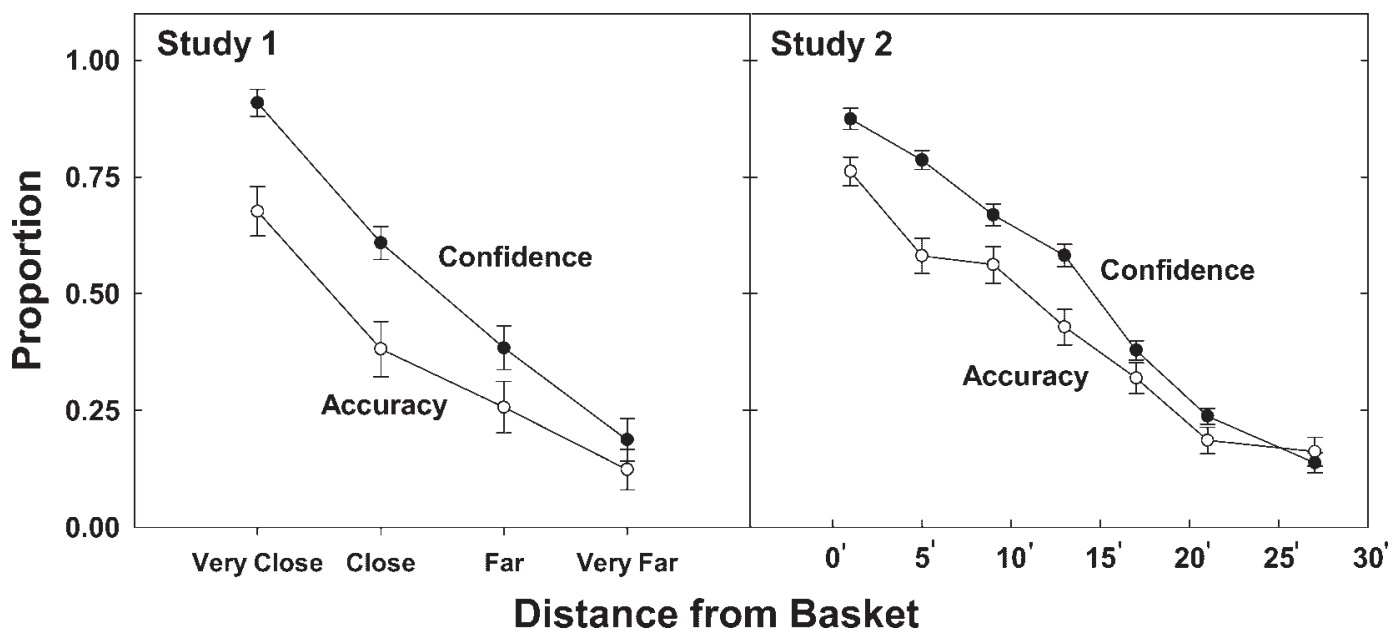

Figure 8. The average of each participant's mean confidence rating and overall accuracy for shots are shown for locations on the court. Error bars show one standard error above and below each point. The left and right panels show results from Study 1 and Study 2, respectively. Study 1 uses four categories of distances (very close, close, far, and very far) by averaging across similar distances from the basket while ignoring the angle of the shot. In Study 2, distances are shown in feet from the basket 
Average confidence ratings are significantly greater than accuracy rates in Study 1 and in Study 2 for the control group (but not the debiased group). Other researchers have argued that overconfidence is a selection artifact that vanishes when items are a 'representative sample' from a population (Gigerenzer, Hoffrage, \& Kleinbölting, 1991). There is no reason, however, to think that the shooting locations on the court constituted a biased sample. As shown in Figure 8, overconfidence and accuracy rates had the expected pattern across all locations on the court. Players were most overconfident when they were closest to the basket, a location with which they presumably had substantial experience. In sum, there is good reason to believe our players were overconfident.

Even though the players appeared overconfident, their overconfidence could have been deliberate. A player's desire to 'look good' to the experimenter or even to himself may have increased reported levels of confidence (Baumeister, 1998). Similarly, judged pleasure may have had a strategic component. Players may have wanted to 'look good' to the experimenter by seeming calmer than they really felt after an easy success or a difficult failure.

Alternative explanations can be proposed for the reduced overconfidence associated with the debiasing procedure in Study 2. Rather than experiencing an actual decrease in their confidence level, the treatment group may have simply reported a decrease per the demands of the experimenter. Or, when making judgments, participants may have simply anchored their judgment on the base rates but not changed their subjective beliefs. An argument to the contrary is participants who were shown the base-rate information also reported less displeasure in the task than the control group, which suggests that the change in confidence ratings reflected a change in actual beliefs. However, it can be countered that the presentation of the base rates may have created a social comparison process that boosted affective experiences.

The positive illusions literature suggests that people are not indiscriminately optimistic (see Armor \& Taylor, 2002). People realize that, in some situations, they can increase their motivation by lowering their expectations (Norem \& Cantor, 1986). Lowering one's expectations also reduces disappointment (Sheppard, Ouellette, \& Fernandez, 1996; van Dijk, Zeelenberg, \& van der Pligt, 2003) and minimizes regret (Kopalle \& Lehman, 2000).

In conclusion, people can increase the pleasure of skill tasks by reducing their overconfidence. Even simple tools, such as base-rate information, increase enjoyment by lowering confidence without hampering performance. However, if accurate calibration improves pleasure, does underconfidence lead to even greater pleasure? While the theory suggests this is true, underconfidence may be costly. Extreme underconfidence can reduce motivation, undermine training, and hamper performance (e.g., Sherman et al., 1981). Too much confidence or too little confidence can both be problematic, but for different reasons. Perhaps the best strategy for maximizing both performance and pleasure is to strive for accurate self-assessments. Although accurate self-assessments are not easy to achieve, a greater awareness of the biases in our beliefs may help us strike a healthy balance between the pre-task benefits of performance and the post-task costs of diminished pleasure.

\section{ACKNOWLEDGMENTS}

The authors thank Jeff Larsen, Jonathan Levav, Janet Schwartz and Danny Kahneman for helpful comments and suggestions. They also thank Anna Cheung for editorial assistance and Rebecca Mayne, Eric Sullivan, and Ryan Leach for assistance in data collection. This research was supported by NSF grant SBR-96-15993.

\section{REFERENCES}

Alicke, M. D. (1985). Global self-evaluation as determined by the desirability and controllability of trait adjectives. Journal of Personality and Social Psychology, 49, 1621-1630. 
Arkes, H. R. (1991). Costs and benefits of judgment errors: implications for debiasing. Psychological Bulletin, 110, 486-498.

Arkes, H. R., Christensen, C., Lai, C., \& Blumer, C. (1987). Two methods of reducing overconfidence. Organizational Behavior and Human Decision Processes, 39, 133-144.

Armor, D. A., \& Taylor, S. E. (2002). When predictions fail: the dilemma of unrealistic optimism. In T. Gilovich, D. Griffin, \& D. Kahneman (Eds.), Heuristics and biases: The psychology of intuitive judgment (pp. 334-347). Cambridge, UK: Cambridge University Press.

Atkinson, J. W. (1957). Motivational determinants of risk taking behavior. Psychological Review, 64, $359-372$.

Atkinson, J. W. (1983). Personality, motivation, and action. New York: Praeger.

Ayton, P., \& McClelland, A. G. R. (1997). How real is overconfidence? Journal of Behavioral Decision Making, 10, 279285.

Baron, J. (1994). Thinking and deciding. New York, NY: Cambridge University Press.

Baumeister, R. (1998). The self. In D. T. Gilbert, S. T. Fiske, \& G. Lindzey (Eds.), The handbook of social psychology (4th ed., pp. 680-740). New York, NY: Oxford University Press.

Baumiester, R. F., Bratslavsky, E., Finkenauer, C., \& Vohs, K. D. (2001). Bad is stronger than good. Review of General Psychology, 5, 323-370.

Baumeister, R. F., Tice, D. M., \& Hutton, D. G. (1989). Self-presentational motivations and personality differences in self-esteem. Journal of Personality, 57, 548-579.

Bazerman, M. (2002). Judgment in managerial decision making. New York, NY: Wiley.

Budescu, D. V., Erev, I., \& Wallsten, T. S. (1997). On the importance of random error in the study of probability judgment. Part I: New theoretical developments. Journal of Behavioral Decision Making, 10, 157-171.

Cohen, J. (1964). Chance, skill, and luck: The psychology of guessing and gambling. Baltimore, MD: Penguin Books.

Cohen, J. (1977). Statistical power analysis for the behavioral sciences (Rev. ed.). New York, NY: Academic Press.

Colvin, C. R., Block, J., \& Funder, D. C. (1995). Overly positive self evaluations and personality: Negative implications for mental health. Journal of Personality and Social Psychology, 68, 1152-1162.

Cooper, A., Woo, C., \& Dunkelberg, W. (1988). Entrepreneurs' perceived chances for success. Journal of Business Venturing, 3, 97-108.

Coughlan, R., \& Connolly, T. (2001). Predicting affective responses to unexpected outcomes. Organizational Behavior and Human Decision Processes, 85, 211-225.

Dawes, R. M., \& Mulford, M. (1996). The false consensus effect and overconfidence: flaws in judgment or flaws in how we study judgment. Organizational Behavior and Human Decision Processes, 65, 201-211.

Erev, I., Wallsten, T. S., \& Budescu, D. V. (1994). Simultaneous over- and underconfidence: the role of error in judgment processes. Psychological Review, 101, 519-527.

Gigerenzer, G., Hoffrage, U., \& Kleinbölting, H. (1991). Probabilistic mental models: a Brunswikian theory of confidence. Psychological Review, 98, 506-528.

Gilbert, D. T., Pinel, E. C., Wilson, T. C., Blumberg, S. J., \& Wheatley, T. P. (1998). Immune neglect: a source of durability bias in affective forecasting. Journal of Personality and Social Psychology, 75, 617-638.

Greenwald, A. G. (1980). The totalitarian ego: fabrication and revision of personal history. American Psychologist, 35 , 603-618.

Hazard, T. H., \& Peterson, C. R. (1973). Odds versus probabilities for categorical events (Tech. Rep. 73-2). McLean, VA: Decisions and Designs, Inc.

Jagacinski, R. J., Isaac, P. D., \& Burke, M. W. (1977). Application of signal detection theory to perceptual-motor skills: decision processes in basketball shooting. Journal of Motor Behavior, 9, 225-234.

Kahneman, D., \& Lovallo, D. (1993). Timid choices and bold forecasts: a cognitive perspective on risk-taking. Management Science, 39, 17-31.

Kahneman, D., \& Tversky, A. (1982). The simulation heuristic. In D. Kahneman, P. Slovic, \& A. Tversky (Eds.), Judgment under uncertainty: Heuristics and biases (pp. 201-208). New York, NY: Cambridge University Press.

Keren, G. (1987). Facing uncertainty in the game of bridge: a calibration study. Organizational Behavior and Human Decision Processes, 39, 98-114.

Keren, G. (1997). On the calibration of probability judgments: some critical comments and alternative perspectives. Journal of Behavioral Decision Making, 10, 269-278.

Klaaren, K., Hodges, S. D., \& Wilson, T. D. (1994). The role of affective expectations in subjective experience and decision making. Social Cognition, 12(2), 77-101.

Kopalle, P. K., \& Lehman, D. R. (2000). Strategic management of expectations: the role of disconfirmation sensitivity and perfectionism. Journal of Marketing Research, 38, 386-394.

Koriat, A., Lichtenstein, S., \& Fischhoff, B. (1980). Reasons for overconfidence. Journal of Experimental Psychology: Human Learning and Memory, 6, 107-118. 
Kunda, Z. (1990). The case for motivated reasoning. Psychological Bulletin, 108, 480-498.

Langer, E. J. (1975). The illusion of control. Journal of Personality and Social Psychology, 32, 311-328.

Langer, E. J., \& Roth, J. (1975). Heads I win, tails it's chance: the illusion of control as a function of the sequence of outcomes in a purely chance task. Journal of Personality and Social Psychology, 32, 951-955.

Lichtenstein, S., \& Fischhoff, B. (1980). Training for calibration. Organizational Behavior and Human Decision Processes, 26, 149-171.

Lichtenstein, S., Fischhoff, B., \& Phillips, L. D. (1982). Calibration of probabilities: the state of the art to 1980. In D. Kahneman, P. Slovic, \& A. Tversky (Eds.), Judgment under uncertainty: Heuristics and biases (pp. 306-334). Cambridge, UK: Cambridge University Press.

McClelland, D. C. (1961). The achieving society. Princeton, NJ: Van Nostrand.

McGraw, A. P. (2003). Emotion-based choices and self-esteem in skill-based tasks. Dissertation Abstracts International, 63(7-B), 3517 (UMI No. AAI3059298).

Mellers, B. A. (2000). Choice and the relative pleasure of consequences. Psychological Bulletin, 126, 910-924.

Mellers, B. A., \& McGraw, A. P. (2001). Anticipated emotions as guides to choices. Current Directions in Psychological Science, 10, 210-214.

Mellers, B. A., Schwartz, A., Ho, K., \& Ritov, I. (1997). Decision affect theory: emotional reactions to the outcomes of risky options. Psychological Science, 8, 423-429.

Mellers, B. A., Schwartz, A., \& Ritov, I. (1999). Emotion-based choice. Journal of Experimental Psychology: General, 128, 332-345.

Neale, M. A., \& Bazerman, M. H. (1985). Perspectives for understanding negotiation: viewing negotiation as a judgmental process. Journal of Conflict Resolution, 29, 33-55.

Norem, J. K., \& Cantor, N. (1986). Defensive pessimism: harnessing anxiety as motivation. Journal of Personality and Social Psychology, 51, 1208-1217.

Paulhus, D. L. (1998). Interpersonal and intrapsychic adaptiveness of trait self-enhancement: a mixed blessing? Journal of Personality and Social Psychology, 74, 1197-1208.

Phillips, L. D., \& Wright, G. N. (1977). Group differences in probabilistic thinking. (Tech. Rep. 76-4). Uxbridge, Middlesex, UK: Brunel University, Decision Analysis Unit, Brunel Institute of Organization and Social Studies.

Robins, R. W., \& Beer, J. S. (2001). Positive illusions about the self: short-term benefits and long-term costs. Journal of Personality and Social Psychology, 80, 340-352.

Roese, N. J., \& Olson, J. M. (Eds.). (1995). What might have been: The social psychology of counterfactual thinking. Mahwah, NJ: Lawrence Erlbaum Associates.

Rozin, P., \& Royzman, E. G. (2001). Negativity bias, negativity dominance, and contagion. Personality and Social Psychology Review, 5, 296-320.

Shepperd, J. A., \& McNulty, J. K. (2002). The affective consequences of unexpected outcomes. Psychological Science, 13, 85-88.

Shepperd, J. A., Ouellette, J. A., \& Fernandez, J. K. (1996). Abandoning unrealistic optimism: performance estimates and the temporal proximity of self-relevant feedback. Journal of Personality and Social Psychology, 70, 844-855.

Sherman, S. J., Skov, R. B., Hervitz, E. F., \& Stock, C. B. (1981). The effects of explaining hypothetical future events: from possibility to probability to actuality and beyond. Journal of Experimental Social Psychology, 17, $142-158$.

Svenson, O. (1981). Are we all less risky and more skillful than our fellow drivers? Acta Psychologica, 47, $143-148$.

Taylor, S. E., \& Brown, J. D. (1988). Illusion and well-being: a social psychological perspective on mental health. Psychological Bulletin, 103, 1193-1210.

Tesser, A. (1988). Toward a self-evaluation maintenance model of social behavior. In L. Berkowitz (Ed.), Advances in experimental social psychology (Vol. 21, pp. 181-227). New York, NY: Academic Press.

van Dijk, W. W., Zeelenberg, M., \& van der Pligt, J. (2003). Blessed are they who expect nothing: lowering expectations as a way of avoiding disappointment. Journal of Economic Psychology, 24, 505-516.

Weiner, B. (1985). An attributional theory of achievement motivation and emotion. Psychological Review, 92, 548-573.

Weinstein, N. D. (1980). Unrealistic optimism about future life events. Journal of Personality and Social Psychology, 39 , 806-820.

Wortman, C. B., Costanza, P. R., \& Witt, T. R. (1973). Effects of anticipated performance on the attribution of causality to self and others. Journal of Personality and Social Psychology, 27, 372-381.

Yates, J. F. (1990). Judgment and decision making. Englewood Cliffs, NJ: Prentice-Hall.

Authors' biographies:

Peter McGraw is an Assistant Professor at the Leeds School of Business, University of Colorado. His major research interest is the interrelation of judgment, choice, and emotion. 
Barbara A. Mellers is a Professor of Marketing and Organizational Behavior at the Haas School of Business, University of California, Berkeley. Her research is on judgment and decision making, emotions, contextual effects, and fairness.

Ilana Ritov is an Associate Professor of Education and Psychology at the Hebrew University of Jerusalem. Her research examines models of human judgment and decision making with an emphasis on regret, errors of omission and commission, evaluation of public goods, and biases in negotiation.

Authors' addresses:

A. Peter McGraw, Leeds School of Business, University of Colorado, 419 UCB, Boulder, CO 80309, USA.

Barbara A. Mellers, Haas School of Business, University of California, Berkeley, CA 94720, USA.

Ilana Ritov, School of Education, Hebrew University, Jerusalem 91905, Israel. 